\title{
Strength Development and Microstructure of Alkali-activated Slag-MgO in Air Curing Condition
}

\author{
Chao-Lung Hwang ${ }^{1}$, Duy-Hai Vo ${ }^{1,2}$, Mitiku Damtie Yehualaw ${ }^{1}$ and $V u$-An $\operatorname{Tran}^{3}$ \\ ${ }^{1}$ Department of Civil and Construction Engineering, National Taiwan University of Science and Technology, Taipei, Taiwan \\ ${ }^{2}$ Department of Civil Engineering, University of Technology and Education-The University of Danang, Danang, Vietnam \\ ${ }^{3}$ Department of Civil Engineering, College of Engineering Technology, Can Tho University, Can Tho, Vietnam
}

\begin{abstract}
The aim of this study is to analysis the effect of $\mathrm{MgO}$ on strength development and microstructure of alkali-activated slag (AAS) in air curing condition. Four mixtures of AAS are prepared using different $\mathrm{MgO}$ content $(0 \%, 5 \%, 10 \%$, and $15 \%$ by weight of slag) at water to binder ratio of 0.4 . The flow, compressive strength, scanning electron microscopy, and X-ray diffraction are tested under relevant standards. The addition of $\mathrm{MgO}$ significantly accelerated the hydration rate of AAS. AAS with adding MgO tended to increase the compressive strength and to reduce the flow. The higher adding $\mathrm{MgO}$ content was associated with higher hydrotalcite-like phase (Ht) formation which improved the microstrure of AAS in the air curing condition.
\end{abstract}

\section{Introduction}

Ordinary Portland cement (OPC) has been widely used for the construction due to the many benefits from good properties to the cost of it. Based on the popular raw materials, the cement production can be easily conducted at many countries in the world. However, there is an estimation of about $1510 \mathrm{kWh}$ consumed to produce one ton of cement as well as this process released about 900 $\mathrm{kg}$ of $\mathrm{CO}_{2}$ into the atmosphere and approximately contributed about $5 \%$ of the global anthropogenic $\mathrm{CO}_{2}$ production [1], [2].

In order to reduce the impacts into the environment as well as ensure sustainable development, using the alternative materials like as fly ash, ground granulated blast furnace slag (GGBFS), rice husk ash, lime stone powder and more to blend with OPC for reducing the consumption of OPC has focused in many researches [3]-[5]. On the other hand, alkali-activated slag (AAS) which is produced with $100 \%$ GGBFS with activators such as sodium hydroxide, sodium silicate or sodium carbonate were considered as an alternative binder in the construction. This has certainly many advantages such as reuse the by-product, reduce the $\mathrm{CO}_{2}$ emissions from cement productions, have similar or better properties to Portland cement. However, these materials have quick setting time and high drying shrinkage or micro-cracks. Different researchers had tried to mitigate the drying shrinkage of AAS. Bakharev et al. [6] used gypsum with $6 \%$ by weight to reduce both of autogenous and drying shrinkage effects of AAS due to the ettringite (Aft) which is formed by the expansion of high voluminous of it. On the other hand, dolomite was also used as an expansion agent due to its content $\mathrm{MgO}, \mathrm{C}_{2} \mathrm{~S}$ and a little amount of $\mathrm{CaO}$. Xu Lingling et al. [7] showed that, the burning condition of dolomite and the dosage of MgObased expansive increased the paste expansion. Expansion of cement increases with the lower burning temperature and the coarser particles size of $\mathrm{MgO}$. Additionally, the expansion increased with increasing the burning condition but the expansion time delayed.

Using magnesia $(\mathrm{MgO})$ to improve the properties of AAS has been studied for long times ago. In their study, Ben Haha et at. [8] showed the performance of AAS with various of $\mathrm{MgO}$ content in different slag. The results illustrated that the main hydration products are still C-S-H gel and hydrotalcite-like phase $(\mathrm{Ht})$ which are formed from the reaction between $\mathrm{MgO}$ and slag. The formation of $\mathrm{Ht}$ increases with an increasing content of $\mathrm{MgO}$. On the other hand, the higher compressive strength in the mixture with high $\mathrm{MgO}$ content. In another research, Fejin et al. [9] used two kind of reactive $\mathrm{MgO}$ to modify the alkali-activated slag and the results showed that the high reactive $\mathrm{MgO}$ produced $\mathrm{Ht}$ quickly and filled in to the macro-pores to form the meso-pores, hence it improves the compressive strength of AAS. Moreover, the high reactive $\mathrm{MgO}$ released more the $\mathrm{Ht}$ lead to the decreasing drying shrinkage. Comparing with the high reactive $\mathrm{MgO}$, the medium reactive $\mathrm{MgO}$ also form the $\mathrm{Ht}$ and $\mathrm{C}-\mathrm{S}-\mathrm{H}$ in the hydration products. However, the rate of reaction of medium reactive $\mathrm{MgO}$ is slower than the high reactive $\mathrm{MgO}$. Moreover, the reactive $\mathrm{MgO}$ were used as an activator for AAS to replace for conventional activators. Another research of Fei Jin et al. [10] used two kinds of reactive $\mathrm{MgO}$ various from $2.5 \%$ to $20 \%$ by weight to activate the GGBFS. The results gave hydrotalcite-like phase and C-S-H gel were also the main hydration 
products and the more reactive $\mathrm{MgO}$ released more hydration products which contribute to higher strength of AAS paste. The hydration products content increased with increasing the $\mathrm{MgO}$ content and curing time.

Even though, numerous researches have been done so far, still the problems are not fully resolved. This study investigated the effect of $\mathrm{MgO}$ on the fresh properties, strength development and microstructure of alkai-activated slag-MgO (AASM) in air curing condition. $\mathrm{MgO}$ was used with $5 \%, 10 \%$ and $15 \%$ by weight of GGBFS, sodium hydroxide and sodium silicate with modulus $\mathrm{SiO}_{2} / \mathrm{Na}_{2} \mathrm{O}$ equal to 0.4 were used as an activator for AAS. The flow and compressive strength up to 28 days were used to estimate the mechanical properties of AASM as well as the XRD and SEM results were used to analysis the microstructure of AASM.

\section{Materials and test method}

\subsection{Materials}

Table 1. Characteristics of binder materials.

\begin{tabular}{|l|l|l|l|}
\hline \multicolumn{2}{|l|}{ Items } & $\mathrm{S} 4000$ & $\mathrm{MgO}$ \\
\hline \multirow{4}{*}{$\begin{array}{l}\text { Physical } \\
\text { properties }\end{array}$} & Specific gravity & 2.98 & 2.91 \\
\cline { 2 - 4 } & Mean particle size & 14.563 & 10.57 \\
\cline { 2 - 4 } & $\begin{array}{l}\text { Specific surface area } \\
\left(\mathrm{m}^{2} / \mathrm{o} \text { ) }\right.\end{array}$ & 1.44 & 1.62 \\
\hline \multirow{4}{*}{$\begin{array}{l}\text { Chemical } \\
\text { composition }\end{array}$} & $\mathrm{SiO}_{2}$ & 33.39 & 9.64 \\
\cline { 2 - 4 } (wt.\%) & $\mathrm{Al}_{2} \mathrm{O}_{3}$ & 14.39 & - \\
\cline { 2 - 4 } & $\mathrm{Fe}_{2} \mathrm{O}_{3}$ & 0.19 & 0.15 \\
\cline { 2 - 4 } & $\mathrm{CaO}^{\mathrm{MgO}}$ & 41.08 & 0.41 \\
\cline { 2 - 4 } & $\mathrm{SO}_{3}$ & 7.22 & 89.2 \\
\cline { 2 - 4 } & $\mathrm{TiO}_{2}$ & 0.11 & 0.75 \\
\cline { 2 - 4 } & $\mathrm{K}_{2} \mathrm{O}$ & 0.50 & - \\
\hline
\end{tabular}

In this study, the GGBFS and $\mathrm{MgO}$ were collected from the companies located in Taiwan used to produce the AASM. Physical and chemical properties of these materials were examined and shown in Table 1 . The mainly component of GGBFS was composed $\mathrm{CaO}$ $(59.75 \%)$ and $\mathrm{SiO}_{2}(26.74 \%)$, while $\mathrm{MgO}$ was pure material with $89.2 \%$ by weight. About the physical properties of these materials, $\mathrm{MgO}$ is presented a finer material than GGBFS based the lower mean particle size (10.57 $\mu \mathrm{m}$ compared with $14.563 \mu \mathrm{m}$, respectively) and higher specific surface area $\left(1.62\left(\mathrm{~m}^{2} / \mathrm{g}\right)\right.$ compared with $1.44\left(\mathrm{~m}^{2} / \mathrm{g}\right)$, respectively).

According to XRD patterns results in Figure 1, GGBFS is mainly found at amorphous phases, while $\mathrm{MgO}$ is pure and well crystallized material. On the other hand, $\mathrm{MgO}$ particle size was significantly smaller than GGBFS. In order to activate the AASM, a combination of sodium hydroxide $(\mathrm{NaOH})$ with a purity higher than
$98 \%$ by weight and sodium silicate $\left(\mathrm{Na}_{2} \mathrm{SiO}_{3}\right.$ with $\mathrm{Na}_{2} \mathrm{O}$ : $8.26 \%$; $\mathrm{SiO} 2: 25.7 \%$ and water: $66.04 \%$ ) was used as an activator solution. Sodium hydroxide solution was mixed in water with molarity of $10 \mathrm{M}$ to dissolve the pellets before casting the samples. Local tap water was used in this study.

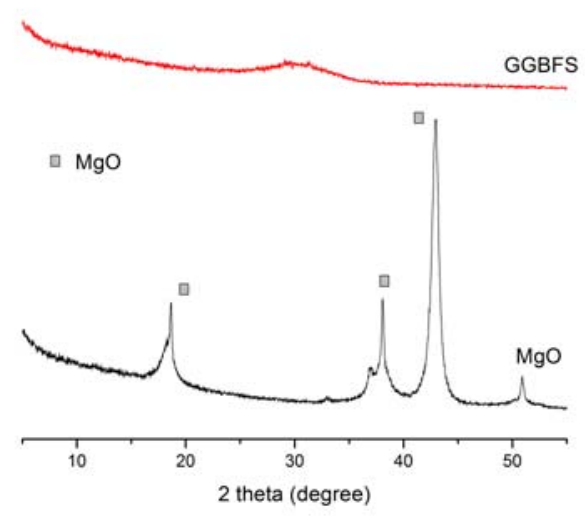

Fig. 1. XRD pattern of raw materials.

\subsection{Mix proportions and test methods}

The alkali-activated slag paste was prepared with proportions of adding $\mathrm{MgO}$ content of $0,5,10$ and $15 \%$ by weight of slag. All the parameters were kept constant, including the modulus $\mathrm{SiO}_{2} / \mathrm{Na}_{2} \mathrm{O}$ ratio of 0.4 ; the proportion of $\mathrm{Na}_{2} \mathrm{O}$ of $4 \%$ by the weight of binder, the water to solid equal to 0.4 and all of them were clearly shown in Table 2. First, sodium hydroxide and sodium silicate were mixed for two minutes to get homogenous activator solution before casting. Then, $\mathrm{MgO}$ was mixed with a part of water to homogenous for two 2 minutes and later slag and all the water were added. After 3 minutes, the activator solution was added and the AAS pastes resulted. For the fresh AAS paste, the flow test

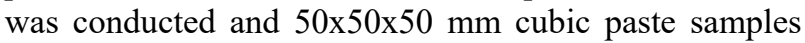
were prepared with two layers as well as the mold was shaken by hand to limit the moisture content. To prevent the evaporation of water from the paste, all the samples were immediately covered by thin film and after 1 day, the samples were demolded and put into the chamber of $60 \% \pm 1 \%$ humidity at $27 \pm 2{ }^{\circ} \mathrm{C}$.

The compressive strength of AAS paste was measured on 1, 7, 28 days according to ASTM C 109 Microstructure analysis test was done for $1 \& 28$ age days specimens by using SEM. Finally, XRD test was conducted with a scanning range from 10 to 50 degree ( 2 theta) for 28 days of curing times.

Table 2. Mixtures design for the alkali-activated slag-Mgo.

\begin{tabular}{|l|l|l|l|l|l|l|}
\hline \multirow{2}{*}{ Samples } & \multicolumn{4}{|l|}{ Ingredient (\%) } & \multirow{2}{*}{$\begin{array}{l}\text { Flow } \\
(\mathrm{cm})\end{array}$} \\
\cline { 2 - 6 } & $\mathrm{w} / \mathrm{b}$ & GGBFS & $\mathrm{MgO}$ & $\mathrm{SiO}_{2} / \mathrm{Na}_{2} \mathrm{O}$ & $\mathrm{Na}_{2} \mathrm{O}$ & \\
\hline M0 & 0.4 & 100 & 0 & 0.4 & 4 & 34 \\
\hline M5 & 0.4 & 95 & 5 & 0.4 & 4 & 31.5 \\
\hline
\end{tabular}




\begin{tabular}{|l|l|l|l|l|l|l|}
\hline M10 & 0.4 & 90 & 10 & 0.4 & 4 & 29.5 \\
\hline M15 & 0.4 & 85 & 15 & 0.4 & 4 & 28 \\
\hline
\end{tabular}

\section{Results and discussion}

\subsection{Flow and compressive strength development}

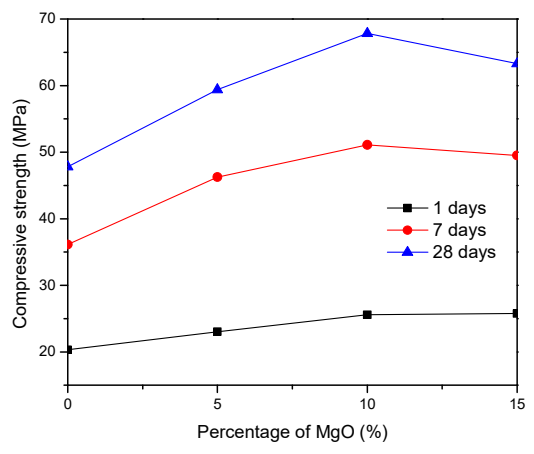

Fig. 2. Strength development of AASM.

The flow of AAS with various $\mathrm{MgO}$ contents is illustrated in Table 2. The flow reduced with increasing contents of the $\mathrm{MgO}$. The flow of samples with $0 \%, 5 \%$, $10 \%$, and $15 \% \mathrm{MgO}$ content were $34 \mathrm{~cm}, 31.5 \mathrm{~cm}, 29.5$ $\mathrm{cm}$, and $28 \mathrm{~cm}$, respectively. The compressive strength of AASM pastes is shown in Figure 2. There is a slight increase in compressive strength of AASM for all proportions containing $\mathrm{MgO}$ on 1 day after demoulding. As expected, the paste with $15 \% \mathrm{MgO}$ exhibits the highest compressive strength in 1 day. This result showed that high $\mathrm{MgO}$ content accelerated the hydration rate of AAS in the early age days [10]. At 28 days of air curing condition, the AASM showed the highest compressive strength with $10 \% \mathrm{MgO}$ content. The compressive strength values of M5, M10, M15 were increased about $24.5 \%, 42.5 \%, 32.4 \%$, respectively, compared with mixture without adding $\mathrm{MgO}$.

$\mathrm{MgO}$ accelerated the hydration reaction of AAS leading to more the hydration products formed [9], based on that, the compressive strength of AASM is higher than AAS without $\mathrm{MgO}$ content. Furthermore, the hydrotalcite-like phase is one of hydration products which is high voluminous to fill into the voids of aggregate to increase the compressive strength. However, the compressive strength of AASM increased with increasing $\mathrm{MgO}$ content up to $10 \%$ and slightly reduced with $15 \% \mathrm{MgO}$ content due to the large proportion of slag replaced by $\mathrm{MgO}$ lead to reduce the aluminosilicate content.

\subsection{X-Ray diffraction analysis}

The X-ray diffraction of AASM at 28 days of curing are portrayed by Figure 3. The results expressed that C-S-H gel and hydrotalcite-like phase are the two main hydration products which are shown on the amorphous phase so the peak are too low [11]. It is found that the $\mathrm{Ht}$ peak was disclosed at $2 \theta \sim 11.7^{\circ}$, the intensity of $\mathrm{Ht}$ peak raise with an increasing in $\mathrm{MgO}$ content and the more unhydrated $\mathrm{MgO}$ were observed at $2 \theta \sim 42.9^{\circ}$ comparing with the mixture without adding $\mathrm{MgO}$. The formation of hydrotalcite-like phase was exhibited by quick reaction between $\mathrm{MgO}$ with the broken $\mathrm{Al}-\mathrm{O}$ and $\mathrm{Si}-\mathrm{O}$ in the slag so the higher $\mathrm{Ht}$ was formed with increasing the $\mathrm{MgO}$ contents. Finally, the shaper peak of C-S-H gel was found at $2 \theta \sim 29.5^{\circ}[12]$.

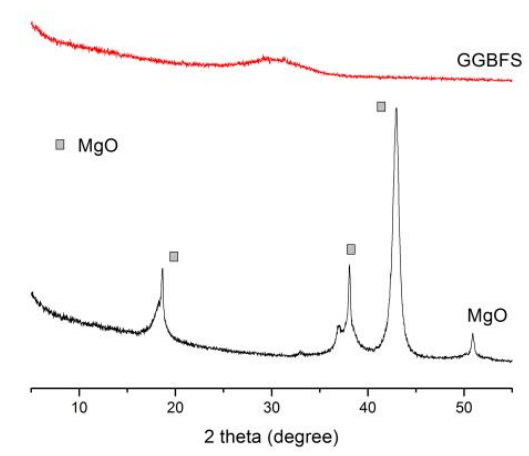

Fig. 3. XRD pattern of AASM at 28 age days.

\subsection{SEM images}

SEM images of AASM paste samples are presented by Figure 4 and 5. The results showed that after demoulding at 1 day, the AASM pastes exhibited high porous structures by un-hydrated slag and $\mathrm{MgO}$ particles. This result illustrated the low compressive strength in 1 day. Two main hydration products of AASM are C-S-H gel and hydratalcite which covered around the slag particles. The extent of formation of hydration products depends on the content of $\mathrm{MgO}$ and it increases with a higher proportion of $\mathrm{MgO}$. Based on that the porosities of AASM paste samples lightly decreased. Especially, hydrotalcite-like phase was found with the mixtures contained adding $\mathrm{MgO}$ after demoulding and the amount of $\mathrm{Ht}$ increased with more the adding $\mathrm{MgO}$ contents lead to the higher compressive strength of mixtures contained more adding $\mathrm{MgO}$.

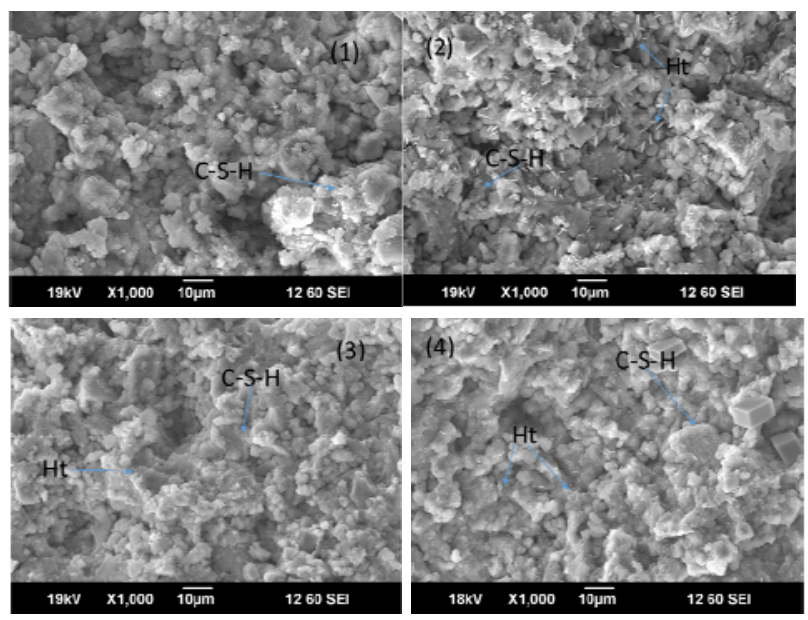

Fig. 4. SEM image of AASM paste samples at 1 day (1) M0; (2) M5; (3) M10; (4) M15. 

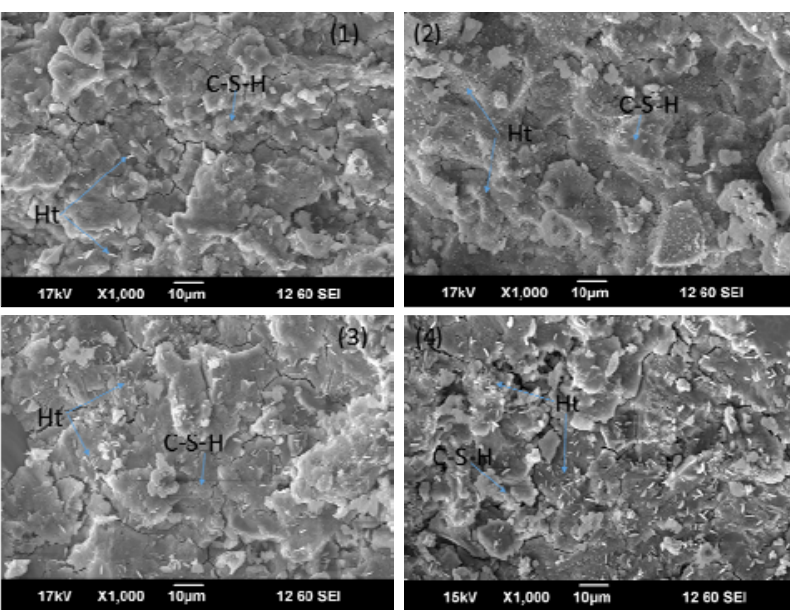

Fig. 5. SEM images of AASM paste samples at 28 days (1) M0; (2) M5; (3) M10; (4) M15.

After 28 days of curing, the denser structures were reported from all AASM samples due to consisting primarily of C-S-H gels. Fibrous Ht were detected in all AAS paste samples with and without adding $\mathrm{MgO}$ content which agreed with the XRD results. On the other hand, all the samples showed the small cracks in the structure because of high shrinkage of AAS.

\section{Conclusions}

Effect of various $\mathrm{MgO}$ contents into the alkali-activated slag on the fresh property, strength development and microstructure were studied. In this research, the AAS were added by $5 \%, 10 \%$ and $15 \% \mathrm{MgO}$ by weight of slag to do the paste samples. The samples were tested the flow, compressive strength and microstructure based on XRD and SEM analysis test. Based on the results of investigation, the following conclusions are drawn:

(1) The $\mathrm{MgO}$ has little effect to accelerate hydration reaction of AAS in the early age and reduce in the flow of AAS paste.

(2) The optimum dosage of $\mathrm{MgO}$ which significantly increased the compressive strength of AAS in the air curing condition is $10 \%$ by weight of slag which contributed by hydrotalcite-like phase with high voluminous to fill into the macropores to form the mesopores hence the micro-structure becomes more denser.

(3) The XRD and SEM analyses illustrated the hydration products are mainly $\mathrm{C}-\mathrm{S}-\mathrm{H}$ gel and Htlike phase to contributes the strength development of AASM. In addition, the microstructure of AASM becomes denser with increasing the curing times by growing up the crystallization of hydration products. On the other hand, increasing the adding $\mathrm{MgO}$ presents the dense structure by more hydration products. However, it is found to decrease the strength with increasing of $\mathrm{MgO}$ content (15\% by weight) since reduce the aluminosilicate content as well as the more late $\mathrm{Ht}$ formation lead to form cracks matrix.

Using $\mathrm{MgO}$ to modify the mechanical properties and microstructure of alkali-activated slag potentially offer for reducing the impacts into environment as well as ensure the sustainable development. However, later $\mathrm{Ht}$ formation should be studied to limit the cracks by high voluminous of Ht. It is hoped that the more researches in this major will support for new greener materials.

\section{Acknowledgment}

The authors gratefully acknowledge the Hwang's research group at the National Taiwan University of Science and Technology (NTUST) for assistance in conducting experimental works

\section{References}

1. E. Worrell, L. Price, N. Martin, C. Hendriks, L. Ozawa-Meida, "Carbon Dioxide Emission from the Global Cement Industry", Annual Review of Energy and the Environment, vol. 26, pp. 303-329 (2001)

2. E. Kwon, J. Ahn, B. Cho, D. Park, "A study on development of recycled cement made from waste cementitious powder", Construction and Building Materials, vol. 83(Supplement C), pp. 174-180 (2015)

3. H. Chao-Lung, B.L. Anh-Tuan, C. Chun-Tsun, "Effect of rice husk ash on the strength and durability characteristics of concrete", Construction and Building Materials, vol. 25(9), pp. 3768-3772 (2011)

4. S. Kumar, R. Kumar, A. Bandopadhyay, T.C. Alex, B. Ravi Kumar, S.K. Das, S.P. Mehrotra, "Mechanical activation of granulated blast furnace slag and its effect on the properties and structure of portland slag cement", Cement and Concrete Composites, vol. 30(8), pp. 679-685 (2008)

5. M.M. Hossain, M.R. Karim, M. Hasan, M.K. Hossain, M.F.M. Zain, "Durability of mortar and concrete made up of pozzolans as a partial replacement of cement: A review", Construction and Building Materials, vol. 116, pp. 128-140 (2016)

6. T. Bakharev, J.G. Sanjayan, Y.B. Cheng, "Effect of admixtures on properties of alkali-activated slag concrete", Cement and Concrete Research, vol. 30(9), pp. 1367-1374 (2000)

7. X. Lingling, D. Min, "Dolomite used as raw material to produce $\mathrm{MgO}$-based expansive agent", Cement and Concrete Research, 35(8), pp. 14801485 (2005)

8. M.B. Haha, B. Lothenbach, G. Le Saout, F. Winnefeld, "Influence of slag chemistry on the hydration of alkali-activated blast-furnace slag Part I: Effect of MgO", Cement and Concrete Research, vol. 41(9), pp. 955-963 (2011)

9. F. Jin, K. Gu, A. Al-Tabbaa, "Strength and drying shrinkage of reactive $\mathrm{MgO}$ modified alkali-activated slag paste", Construction and Building Materials, vol. 51(Supplement C), pp. 395-404 (2014) 
10. F. Jin, K. Gu, A. Al-Tabbaa, "Strength and hydration properties of reactive $\mathrm{MgO}$-activated ground granulated blastfurnace slag paste", Cement and Concrete Composites, vol. 57(Supplement C), pp. 8-16 (2015)

11. H.A. Abdel-Gawwad, "Effect of reactive magnesium oxide on properties of alkali activated slag geopolymer cement pastes", Ceramics-Silikaty, vol. 59 (1), pp. 37-47 (2015)

12. S. Bernal, J. Provis, V. Rose, R. Mejia, "HighResolution X-ray Diffraction and Fluorescence Microscopy Characterization of Alkali-Activated Slag-Metakaolin Binders", Journal of the American Ceramic Society, vol. 96 (6), pp. 1951-1957 (2013). 